\title{
Ensinar (Filosofia) com a solidão
}

\author{
Luis Cesar Fernandes de Oliveira ${ }^{1}$
}

\begin{abstract}
Resumo
O presente trabalho tem por objetivo analisar a possibilidade de ensinar filosofia com a perspectiva da solidão, principalmente a partir da obra Assim falou Zaratustra, escrita entre 1883 e 1885, pelo filósofo alemão Friedrich Nietzsche. Para tal empreitada, primeiramente, analisaremos como o conceito de solidão pode estar atrelado à amargura e à tristeza, assumindo um sentido pejorativo para a conservação da vida humana ao se considerar o surgimento da faculdade da memória e o desenvolvimento da consciência. Outrossim, será abordada a distinção entre solidão e abandono oferecida na obra. Por fim, será erguida a questão da relevância de tais relações conceituais para o ensino de filosofia.
\end{abstract}

Palavras-chave: filosofia; ensino; solidão.

Palavras-chave: Filosofia; Identidade Filosófica; Prática de Ensino de Filosofia.

\section{Teaching (Philosophy) with loneliness}

\begin{abstract}
This paper aims at analysing the possibility of teaching philosophy under the perspective of solitude, mainly based on the work Thus Spoke Zarathustra, written by the German philosopher Friedrich Nietzsche between 1883 and 1885. For this purpose, firstly, it is analysed how the concept of solitude can be tied to bitterness and sadness, assuming a pejorative sense for the conservation of human life by considering the emergence of the faculty of memory and the development of consciousness. Furthermore, the distinction between solitude and loneliness found in such work is addressed. Finally, the relevance of such conceptual relations for the teaching of philosophy is discussed.
\end{abstract}

Keywords: Philosophy; Teaching; solitude.

\footnotetext{
1 Doutorando em Filosofia pela UERJ, mestre em filosofia pela UERJ e também mestre em Memória Social pela UNIRIO, professor de Filosofia em dedicação exclusiva no Centro Federal de Educação Tecnológica Celso Suckow da Fonseca - CEFET/RJ, atuando como docente e vice-coordenador de Filosofia no Departamento de Ensino Médio e Técnico, na Pós-Graduação Lato Sensu em Ensino de Filosofia e como colaborador no Programa de Pós-Graduação em Filosofia e Ensino. luiscesar1976@gmail.com
} 


\section{Ensinando a ser "comum" e marginalizando a solidão}

Corriqueiramente, o conceito de solidão é acoplado à amargura e à tristeza, relacionado à existência deplorável, na qual alguém carece da segurança da convivência em grupo. Possivelmente, esse acochambrado de conceitos se define pelo sentimento gregário de conservação da espécie, ao qual Friedrich Nietzsche se referiu em sua Genealogia da moral, de 1888. Nessa obra, o autor esclarece que a natureza criou no homem uma faculdade específica, a memória, que viabilizou a lembrança dos perigos e o desenvolvimento de regras de comunicação entre os indivíduos, para a conservação da espécie. Tal disposição da natureza em criar a memória, e cada vez mais tornar o homem um ser gregário, pode ter produzido nele o sentimento gregário que rechaça a solidão de modo enfático até aos dias atuais.

Segundo o filósofo, a natureza desenvolveu no homem uma faculdade que Ihe possibilitasse se tornar regular. Tal desenvolvimento ocorreu porque a humanidade necessitou agregar-se socialmente para se proteger de diversos perigos. Como o homem é o animal mais frágil da natureza, ainda segundo Nietzsche, alguns indivíduos mais robustos, que conseguiam se proteger de certo modo, submeteram os demais aos castigos mais horrendos para que sempre lembrassem que precisavam evitar os perigos. Com o decorrer da história, os castigos foram sendo intensificados ou amenizados de acordo com a regularidade de prevenção dos perigos. No entanto, os perigos não eram somente externos, mas também internos ao grupo humano. A ordem social também foi definida através da relação entre culpa e castigo. Toda sorte de castigos sanguinários foi aplicada, de acordo com o tipo de necessidade. Desse modo, a memória se desenvolveu até o homem se tornar responsável por suas ações e, assim, pela conservação da espécie. (Cf. NIETZSCHE, 2009, p. 46). Ao lembrar da regra a ser seguida, cada homem se tornou responsável por si mesmo, conservando também o grupo humano ao qual pertencia.

O processo que consentiu ao homem tornar-se senhor de si e responsável por sua espécie é intrínseco ao desenvolvimento da consciência. Emaranhada com a memória, surgiu a capacidade de o homem entender-se como senhor de si mesmo, de seus atos, e, contemporaneamente, responsável pelas duas faces da existência 
que lhe são possíveis reconhecer: si mesmo e os outros (o grupo humano). Desse modo, lembrar de si equivale a poder dizer algo de si, para si mesmo e para os outros, ou seja, manter a comunicação das condições e possibilidades de conservação da espécie. Em sentido estritamente gregário, o indivíduo serve para a preservação da espécie, através da responsabilidade em cumprir com o dever moral incutido através dos castigos. Ressalta-se acerca disso o que Nietzsche esclarece:

Esta é a longa história da origem da responsabilidade. A tarefa de criar um animal capaz de fazer promessas, já percebemos, traz consigo, como condição e preparação, a tarefa mais imediata de tornar o homem até certo ponto necessário, uniforme, igual entre iguais, constante, e, portanto, confiável. O imenso trabalho daquilo que denominei "moralidade do costume" (Cf. Aurora, §9, 14, 16) - o autêntico trabalho do homem em si próprio, durante o período mais longo da sua existência, todo esse trabalho pré-histórico encontra nisto seu sentido, sua justificação, não obstante o que nele também haja de tirania, dureza, estupidez e idiotismo: com a ajuda da moralidade do costume e da camisa de força social, o homem foi realmente tornado confiável (NIETZSCHE, 2009, 44).

A partir da ampliação da memória e da consciência, a confiança foi definida como o critério fundamental para a distinção entre a vida gregária e o seu contrário. Um indivíduo só pode ser considerado confiável caso tenha consciência de si como responsável por si mesmo e por seu grupo ou por seu povo. Caso contrário, não se pode conceber que um solitário não seja uma ameaça à vida gregária, à vida comunitária. Ações isoladas tornaram-se sempre suspeitas. Pensamentos que não estão de acordo com as regras de conservação da espécie e da dignidade do indivíduo responsável passaram a ser enxergados como perigosos e caluniadores da verdadeira perspectiva humana, que é a autoconservação.

Se observada a partir desse prisma, a condição de confiança estabelecida entre os homens ocorreu por um processo de forjadura de conduta. Em sentido faceto, houve toda uma "educação" por meio de castigos para que o homem se tornasse consciente, responsável e, por isso, confiável. Castigando em função da vida gregária, os homens foram desenvolvendo um modo de "ensinar" a cumprir as regras e sustentar a convivência. Um ensino que precisou do auxílio da dor, pois como salientou Nietzsche: "Grava-se algo a fogo, para que fique na memória: 
apenas o que não cessa de causar dor fica na memória [...]" (2009, p. 46). E fixando na memória, ensinou-se a obedecer às regras sociais de conduta, ensinou-se a convivência em grupo.

A partir disso, pode-se indagar se o conceito de solidão está atrelado a um sentido ameaçador e, portanto, perigoso para cada um e para o grupo. Provavelmente, o afastamento do grupo se tornou uma ameaça à conservação da vida coletiva. E, provavelmente, as pessoas também carregam até hoje tal sentimento avesso à solidão porque atrelam a ela aquele sofrimento dos castigos e a ameaça de extinção da espécie.

\section{A solidão que ensina a Zaratustra}

Sob olhares imprecisos, pode parecer intrigante na análise de Nietzsche que a faculdade que viabilizou a conservação da espécie precisou ser forjada com insistentes castigos. Isso porque aparece bastante naturalizado que a sobrevivência possui prioridade sobre qualquer condição, mesmo que pela via da submissão e da tortura. Isso também porque pouco ou nada se questiona os motivos pelos quais se aceita o castigo e as penalidades quando são impostos e admitidos socialmente. Além de ser admissível que se "eduque" com castigos, recorre-se sempre à aprovação da maioria para se validar o sofrimento daquele que descumpre o dever moral. Basta observar que a história da humanidade é marcada pela correlação entre desobediência e punição com o ferimento do corpo.

Normalmente não se inquire fortemente sobre a validade das imposições e das punições, pois elas fazem parte de uma condição de sobrevivência. O máximo que se pode pensar é que as regras mudam, mas jamais se pode deixar de punir, mesmo que de modo menos grosseiro. O adestramento não pode cessar, pois é preciso manter os indivíduos conectados de algum modo preventivo. Assim, socialmente se prefere admitir que os sofrimentos causados (pelos castigos) para a conservação da espécie são mais válidos do que as condições que uma vida solitária pode favorecer. Assim, a solidão se tornou a pior condição de vida que um homem pode experimentar, pois contradiz as normas de conservação da espécie e oferece perigo à ordem estabelecida. Afinal, alguém que se lance viver de modo 
solitário não pode inspirar confiança pelo simples fato de não se prontificar a se ocupar com o cumprimento das regras de conduta às quais o meio de convivência gregário exige.

Diante disso, pode não ser somente ao sofrimento que se lança certo repúdio quando rechaçam a solidão. É bem possível que os homens carreguem consigo o mais terrível medo de extinção desde os tempos mais remotos. Razão pela qual se preza demasiadamente pela longevidade, seja nas súplicas religiosas ou nas séries cotidianas de atividades para a conservação do corpo pelo maior número de anos possível. Todavia, as pessoas também podem sentir, na solidão, as dores e os calafrios herdados em seus corpos adestrados na longínqua e sanguinária história da humanidade. Pois a solidão possivelmente está associada ao antigo medo de sofrer com os castigos destinados aos contraventores, assim como pode ser atrelada ao medo feroz de não contar com o condicionado desejo de aprovação do grupo. Afinal, os homens sofreram, ou aprenderam, na pele a preferir sempre a segurança da vida comunitária.

Diante do medo da rejeição do grupo que se pode também entrever outro receio importante: o temor do abandono, do não-acolhimento, da nãoadaptação. Ora, se a história da humanidade é um percurso de castigos e torturas para que se aprenda a sobreviver, é provável que se preferiu forçosamente que a sobrevivência em grupo seja uma excelência. Mesmo que os castigos tenham engendrado a dor na carne humana, em toda a história da humanidade, fez-se preferível sofrer em grupo do que solitariamente. Os riscos são menores na vida comunitária. Por isso, ela se eleva diante de qualquer isolamento, de qualquer vida que se diferencie. Por isso, a vida solitária foi lançada ao cargo do risco e da desolação, acreditando-se que nada pode ser excelente senão através e em função da vida em grupo, conservada em sua normalidade. E se a excelência humana é ser adaptado à vida gregária, mesmo carregando as dores dos castigos, nada pior do que ser visto como um degenerado, um contraventor que tem tal fama por viver com a solidão. Pois nesse molde, o solitário seria um abandonado pela estima do grupo; seria um renegado socialmente e, por isso, um sofredor acometido pela insanidade do isolamento. Ainda que seja abandonado por si mesmo ao isolamento, ainda que seja aparentemente uma preferência deliberada, 
vale proferir que, diante da segurança da vida social, sua escolha é um desalento num modo de vida inapropriado à alegria.

O desejo de manter-se sempre acolhido e bem acomodado no meio de coexistência gregário oportuniza ao homem uma confusão que o personagem principal Zaratustra ${ }^{2}$ experimentou: a confusão entre solidão e abandono. Como todos os homens foram ensinados a acreditar que a rejeição é oriunda de um tipo de vida solitário, Zaratustra não foge à regra nesse caso específico.

A experiência ocorre na terceira parte da obra Assim falou Zaratustra, quando a solidão ensina ao personagem uma distinção importante. $O$ diálogo ocorre após uma longa e exaustiva parte da jornada na qual Zaratustra decepciona-se seriamente com seus interlocutores. Após um longo discurso sobre os personagens que encontrou em suas aventuras, como os cadáveres e palhaços, os fiéis renegados por sua covardia (característica própria da espécie humana), Zaratustra abandona uma cidade que tanto estima (chamada A Vaca Pintalgada) e se alegra com a proximidade do retorno à sua caverna e aos seus dois animais ${ }^{3}$. Assim que regressa à solidão em sua caverna, exclama seu nome e observa que ela Ihe aponta o dedo, ameaçando e rindo para ele como fazem as mães com seus filhos. Inicia-se, portanto, um ensinamento filosófico da solidão para com seu filho dileto, Zaratustra. Pode-se afirmar que é um ensinamento filosófico porque possui uma característica bem específica do filosofar, que é buscar no mundo o entendimento das situações e adversidades a partir de um estranhamento. $\bigcirc$ que ela ensina ao personagem é a distinção entre solidão e abandono, como se pode observar no trecho:

Ó solidão! Ó solidão, pátria minha! Por tempo demais vivi selvagemente, em selvagens terras alheias, para não regressar a ti sem lágrimas!

Agora apenas me ameaça com o dedo, como fazem as mães, agora sorri para mim, como sorriem as mães, agora apenas fala: "E quem foi aquele que um dia, como um vendaval, escapou tempestuosamente de mim? -

\footnotetext{
2 Personagem principal da obra Assim falou Zaratustra, escrita entre 1883 e 1885, por Friedrich Nietzsche.

3 Os animais de Zaratustra são uma águia, animal mais altivo por voar alto e enxergar num lance de olhar o que está mais distante na terra, e uma serpente, animal mais prudente porque está junto à terra.
} 
- que partindo exclamou: por tempo demais fiquei junto à solidão, então desaprendi de calar! Isso - aprendeste agora?

Ó Zaratustra, sei de tudo; e também que no meio de muitos homens estavas mais abandonado, único que és, do que jamais estiveste comigo!

Uma coisa é o abandono, outra é a solidão. Isso - aprendeste agora! E que sempre serás, entre os homens, selvagem e alheio:

- selvagem e alheio ainda quando te amem: pois antes de tudo eles querem ser poupados! (NIETZSCHE, 2011, p. 174-175).

Nota-se que a solidão indaga sobre o que Zaratustra aprendeu no trato com os homens e quais comparações pode fazer sobre sua experiência com ela. Sua inquirição indica que ele pode estar decepcionado e precisa ainda aprender algo mais. A seguir, exclama que tudo sabe e que o personagem estava abandonado ao conviver com os homens. Contudo, ele mesmo havia abandonado a solidão anteriormente para ensinar o que havia aprendido em sua companhia. Inicialmente, parece que Zaratustra aprendeu que precisava ensinar algo, mas retornou, após longo percurso, decepcionado e cansado. Na verdade, os homens haviam compreendido mal seus preciosos ensinamentos, pois não houve entendimento entre aqueles acostumados com a comunicação gregária e a fala de um solitário. Demasiado diferente se tornou o personagem Zaratustra daqueles adestrados por ensinamentos da vida gregária.

Na sequência, a solidão diz a Zaratustra como ele é enquanto solitário, e o que se tornou quando partiu para o meio dos homens. Ele se tornou abandonado, mesmo sendo único, porque os homens não foram boas companhias. Eles foram cadáveres, palhaços e fiéis traidores de seus ensinamentos ${ }^{4}$. Por enxergar isso, a solidão the ensina a diferença crucial que o abandono contém. Ela inicia um discurso de diferenciação de si mesma em relação ao abandono. Ensina que com ela, ele pode se sentir consigo mesmo, confessando tudo a si próprio, todos os

\footnotetext{
4 Zaratustra ensinou o Übermensch, o Além-do-homem. Seu projeto era ensinar aos homens a transvaloração de todos os valores morais, a superação de si mesmo. Observa-se no "Prólogo" da obra que o personagem ensina a transvaloração de todos os valores anunciando o "Além-do-homem", a superação do homem: "Quando Zaratustra chegou à cidade mais próxima, na margem da floresta, ali encontrou muita gente reunida na praça; pois fora anunciado que um equilibrista andaria na corda. E Zaratustra assim falou à gente: Eu vos ensino o super-homem. O homem é algo que deve ser superado. [...]". (NIETZSCHE, 2011, p. 13).
} 
sentimentos escondidos, todos os seus segredos. Ele pode dizer o que precisa sem rodeios, pois a comunicação se faz com fluidez na solidão. Sua conversa é consigo, não tendo motivos para não saber das coisas mais íntimas. Porque ainda que se queira mentir para si mesmo, fingindo, seu coração sabe mais de si do que os outros. Sua solidão é a sua morada confiante, mesmo que nem sempre a mais confortável. Ao menos é a mais honesta e não lhe impõe castigos por seus erros. Ao invés de punir, ela lhe traz de volta ao seu lugar de superação de si, oferecendo-lhe uma companhia que não quer a sua conservação. Sendo assim, ela é uma condição que não conserva, porque não se inscreve como meta. Diversamente da circunstância gregária, que tem a si mesma como meta de conservação, a solidão é a condição na qual o objetivo não é conservar-se, mas o solitário é a meta de superação de si mesmo. A partir desse movimento que a solidão viabiliza, é improvável que algum solitário esteja buscando apenas a conservação de si através do isolamento, pois o movimento de abertura para a superação de si lhe impede de acomodar-se. Ao contrário, arremessa-o fortemente para fora, para o mundo que lhe toca cotidianamente com os estímulos externas.

\section{Solidão e consciência}

Possivelmente, o costume em admitir que a solidão é nociva à vida segura e alegre, e também à longevidade, seja reafirmado no cotidiano com a necessidade de conservação. Entretanto, isso acontece em contradição à necessidade de transformação pessoal, pois além de desejar manter-se vivo, o homem necessariamente está em constante transformação de si mesmo. Ele excede inevitavelmente as suas desventuras. Mas o que realmente incomoda a Nietzsche nessa contradição entre tender à conservação, com o seu aspecto gregário, e a inevitável transformação pessoal, em seu aspecto solitário ${ }^{5}$ da superação de si, é a hipervalorização da consciência em todo o processo.

Aparentemente, a consciência se apresenta como juíza do conflito, ao ponto de se conceber como a fonte decisiva das ações. No entanto, ela pode ser

5 O aspecto solitário da superação de si é corroborado pela hipótese de que, mesmo que a pessoa humana seja castigada ou influenciada nas diversas circunstâncias da vida, as transformações cruciais ocorrem na solidão. Sobre o assunto, será analisado neste trabalho o aforismo 321 de A gaia ciência. 
apenas uma faculdade auxiliar em todo a situação, tendendo mais para a conservação do que para a superação de si. Provavelmente, em vários casos, não seja exclusivamente conservadora, cabendo também o subsídio à superação de si no âmbito da solidão. Contudo, seu desenvolvimento tende muito mais à conservação da espécie.

Para refletir com Nietzsche sobre o assunto, observa-se que sua explicação, enfatizada no aforismo 354 de A gaia ciência, parte da conjectura de que a consciência surgiu da necessidade de comunicação humana, desde tempos longínquos, para a sobrevivência. Precisou-se da consciência para que houvesse comunicação entre os membros do grupo e pudessem não apenas estabelecer relações de trocas. Necessitou-se de, principalmente, conservar a espécie num ambiente seguro e pretensamente estável, que passou a ser denominado como "sociedade". Assim, formou-se uma associação entre os homens, possibilitando aparentemente a segurança e a longevidade, mesmo que pela dor dos castigos. Sobre o assunto, observe-se como o filósofo apresenta sua hipótese de que:

[...] a consciência desenvolveu-se apenas sob a pressão da necessidade de comunicação - de que desde o início foi necessária e útil apenas entre uma pessoa e outra (entre a que comanda e a que obedece, em especial), e também se desenvolveu apenas em proporção ao grau dessa utilidade. Consciência é, na realidade, apenas uma rede de ligação entre as pessoas - apenas como tal ela teve que se desenvolver: um ser solitário e predatório não necessitaria dela (NIETZSCHE, 2001, p. 248249).

Percebe-se que, após supor que a consciência tenha sido desenvolvida apenas para a comunicação e, consequentemente, para a conservação da espécie, Nietzsche afirma que "um ser solitário e predatório" não teria necessidade dela. Ora, se é assim, cabe indagar se a consciência é importante na superação de si, vista como um processo vivido na solidão.

Justifica-se tal inquérito também por outros motivos expostos pelo filósofo. Um deles é o fato de nossos pensamentos, nossas ações e nossos sentimentos chegarem à consciência somente após um longo e penoso trajeto de adestramento social. Como visto anteriormente, foi através de castigos que o homem pode se lembrar de si mesmo e se tornar responsável socialmente. Nesse 
percurso, foi preciso que se desenvolvesse a consciência, contemporaneamente à memória e à comunicação com palavras, para que fosse possível a conservação da espécie. Tornou-se necessário que o homem "soubesse" de si, do outro e do grupo. Que "soubesse" também como se sentia e o que pensava. "Saber", nesse caso específico, significa ter consciência, lembrar de si mesmo e ter a dimensão de que é, ao mesmo tempo, distinto e igual ao outro. Distinto porque não confunde a sua responsabilidade pessoal e social com a do outro. Igual porque sabe que o outro possui responsabilidade também pessoal e social, mas que é dele e não sua. Assim, o indivíduo "sabe" de si, como unidade integrante do grupo, do mesmo modo que "sabe" do grupo como unidade que contém tantas outras unidades componentes.

Segundo Nietzsche, essa "sabedoria" de si é fruto de um desenvolvimento mediano, ao qual os homens foram submetidos através de castigos para a sobrevivência, intensificando o poder preservativo da consciência, como se pode observar:

O fato de nossas ações, pensamentos, sentimentos, mesmo movimentos nos chegarem à consciência - ao menos parte deles - é consequência de uma terrível obrigação que por longínquo tempo governou o ser humano: ele precisava, sendo o animal mais ameaçado, de ajuda, proteção, precisava de seus iguais, tinha de saber exprimir seu apuro e fazer-se compreensível - e para isso tudo ele necessitava antes de "consciência", isto é, "saber" o que the faltava, "saber" como se sentia, "saber" o que pensava (NIETZSCHE, 2001, p. 249).

Observe-se que todo o conhecimento de si, nos termos da consciência, não tardou chegar até aos dias atuais senão como modo de vida atrelado às circunstâncias gregárias. Os homens, por isso, carregam em si o sentimento ilusório de que fazem jus à autonomia, como se fossem os responsáveis por suas ações. Mas, na realidade, são apenas reprodutores das ações modelares e ajustadas às regras sociais estabelecidas, das ações dignas de serem repetidas insistentemente. Tudo isso Ihes foi ensinado através das dores dos castigos. Todo o ensinamento que houve no processo de socialização teve como base a tortura como modo de fazer marcar na carne o dever social a ser cumprido. Por isso, os homens se iludem achando que pensam de modo autônomo quando entendem que a consciência 
delibera. Se alegram fantasiosamente quando admitem que o pensamento é sempre fruto da reflexão consciente. E, finalmente, entendem que as ações mais acertadas são sempre oriundas das deliberações da consciência. Tudo isso devém da única crença, ou se pode dizer também aprendizado, de que o conhecimento de si é algo verdadeiramente individual. Não percebem que aquilo a que concebem como individual é apenas uma média obtida entre as necessidades de sobrevivência e a tolerância com a multiplicidade dos corpos individuais.

\section{Conclusão}

A tendência a acreditar que a consciência' ${ }^{6}$ é determinante na atividade do pensamento, no sentimento e nas ações é oriunda de um desenvolvimento gregário de adestramento dos homens individuais. Para melhor ilustrar tal perspectiva, observe-se, primeiramente, como Nietzsche esclarece sobre a atividade do pensamento e a consciência de si:

O ser humano, como toda criatura viva, pensa continuamente, mas não o sabe; o pensar que se torna consciente é apenas a parte menor, a mais superficial, a pior, digamos: - pois apenas esse pensar consciente ocorre em palavras, ou seja, em signos de comunicação, com o que se revela a origem da própria consciência. Em suma, o desenvolvimento da linguagem e o desenvolvimento da consciência (não da razão, mas apenas do tomar-consciência-de-si da razão) andam lado a lado. Acrescente-se que não só a linguagem serve de ponte entre um ser humano e outro, mas também o olhar, o toque, o gesto; tomar-consciência das impressões de nossos sentidos em nós, a capacidade de fixa-las e como que situá-las fora de nós, cresceu na medida em que aumentou a necessidade de transmiti-las a outros por meio de signos. O homem inventor de signos é, ao mesmo tempo, o homem cada vez mais consciente de si; apenas como

\footnotetext{
- Segundo o que está exposta em A gaia ciência, Nietzsche não está preocupado em tratar da oposição entre sujeito e objeto, pois este é um papel deixado para os teóricos do conhecimento, que se ocupam com questões das malhas da gramática, ou metafísica do povo. Notoriamente, o autor descarta a possibilidade de se fazer uma teoria do conhecimento que se enverede pela distinção entre sujeito cognoscente e objeto cognoscível, assim como não admite que esteja abordando a oposição kantiana entre fenômeno e coisa em si. Conclui o aforismo afirmando que não podemos tratar de tais assuntos porque não temos um órgão para o conhecer, pois apenas acreditamos que existem sujeitos e objetos, interior e exterior. (Cf. NIETZSCHE, 2001, p. 251). Desse modo, descarta-se a possibilidade de problematizar sobre a objetividade e a subjetividade da consciência e da solidão, porque sujeito e objeto são apenas crenças engendradas no mesmo processo de criação da memória e da consciência, apenas para estabelecer critérios de convivência entre os homens.
} 
animal social o homem aprendeu a tomar consciência de si - ele o faz ainda, ele o faz cada vez mais (NIETZSCHE, 2001, p. 250).

A atividade do pensamento, nesses termos, não se restringe à reflexão consciente, mas é também anterior. Cabe à consciência ser um refletor impreciso dos movimentos corpóreos, tais como "o olhar, o toque, o gesto", assim como de todas as capacidades corpóreas. Todavia, o que está em jogo por enquanto não é se a consciência é a única capaz de proporcionar a comunicação entre os homens. O principal é saber que ela assume um papel de fixadora das impressões humanas fora do indivíduo. Ela se serve de outras capacidades do corpo para transformar e fixar fora dela as impressões obtidas. Tal fixação se institui em signos de comunicação, que servem prioritariamente aos interesses gregários, ou seja, ao objetivo de conservar a espécie. Por isso, um modo de vida solitário, que não seja submetido exclusivamente à consciência, equivale a uma existência abominável socialmente. E mesmo que as ações sejam individuais estritamente, o que prevalece através da consciência é que "[...] tão logo as traduzimos para a consciência, não parecem mais sê-lo..." (NIETZSCHE, 2001, p. 249). Da mesma maneira, quando se refere aos sentimentos humanos, basta que a consciência explique um sentimento para que deixe de ser do indivíduo e se torne de posse da circunstância fixadora e moralizante da vida social.

Assim, quanto à questão sobre o valor da consciência na superação de si, parecendo haver uma discordância entre o seu interesse exclusivamente gregário e o interesse de um solitário, primeiro é preciso lembrar que a comunicação entre os homens ocorre por meios diversos. A seguir, é necessário também considerar que a consciência não é senão integrante do corpo, como faculdade que reflete todo os movimentos que os instintos direcionam secretamente. Segundo Nietzsche, em além do bem e do mal, no "Capítulo primeiro", quando se está consciente, não há oposição decisiva ao que é instintivo, pois são os instintos que guiam em segredo o pensamento consciente de um filósofo. (Cf. NIETZSCHE, 2005, p. 10-11). Desse modo, pode-se pensar numa conciliação entre a consciência e a solidão. Ora, se o homem atual é consciente e guiado em segredo, na maior parte, por seus instintos, mesmo que esteja solitário, não exclui a necessidade de comunicação de suas mais cruciais transformações. Como Zaratustra, que outrora desejou presentear os 
homens ensinando a superação de si na figura do "Além do homem", é possível pensar num ensino de filosofia que considere a articulação entre a característica gregária da consciência e a perspectiva solitária de superação de si mesmo.

Tal articulação precisaria partir da premissa de que ninguém muda ninguém, mas que a circunstância que ocasiona as transformações para a superação de si ocorre solitariamente. Na mais árdua solidão, são vivenciadas todas as influências e todos os movimentos instintivos que encaminham nossas escolhas. Na realidade, não se escolhe nada exclusivamente com a consciência, pois o trabalho secreto dos instintos, ao relacionarem-se com o mundo ao qual compõem, é efetuado na surdina da solidão. Então, que o ensino seja de tal modo que não querer mudar ninguém seja uma prerrogativa, como Nietzsche esclarece no aforismo 321 de $A$ gaia ciência:

\begin{abstract}
Nova precaução. - Deixemos de pensar tanto em castigar, repreender e melhorar! Raramente mudamos um indivíduo; e, conseguindo fazê-lo, talvez tenhamos conseguido algo mais, sem o perceber: nós fomos mudados por ele! Cuidemos, isto sim, para que nossa influência em tudo o que há de vir compense e ultrapasse a dele! Não lutemos em combate direto! — toda repressão, punição e desejo de melhorar outros equivale a isso. Mas elevemos tanto mais a nós mesmos! Demos cores cada vez mais brilhantes ao nosso exemplo! Obscureçamos o outro com nossa luz! Não! Não queremos ficar obscuros por sua causa, como todos os que castigam e não se satisfazem! É melhor que nos afastemos! Desviemos o olhar! (NIETZSCHE, 2001, p. 214).
\end{abstract}

A partir do ponto de vista de articulação entre a consciência e a solidão, é possível cogitar que o ensino, principalmente o de filosofia, pode se dar de um modo que exclua o castigo e o adestramento. É possível um ensino de filosofia com a solidão, que considere a consciência como uma aliada, e que preze pela superação de si. Caso observemos o "Abecedário Gilles Deleuze", o papel do professor é reconciliar o estudante com sua solidão, como se pode verificar nos vídeos do Abecedário Gilles Deleuze, onde o filósofo afirma:

Para mim, duas coisas são importantes: a relação que temos com os estudantes é ensinar que eles fiquem felizes com sua solidão. [...] Temos de ensinar-Ihes os benefícios da sua solidão, reconciliá-los com sua solidão. Esse era o meu papel de professor (DELEUZE, 1988-1989). 
Se essa prerrogativa estiver correta, possivelmente seja pelo que Nietzsche salientou: "Deixemos de pensar tanto em castigar, repreender e melhorar! Raramente mudamos um indivíduo; e, conseguindo fazê-lo, talvez tenhamos conseguido algo mais, sem o perceber: nós fomos mudados por ele!" (Cf. NIETZSCHE, 2001, p. 214). Sendo assim, o que realmente importa no ensino, nessa perspectiva, é que o professor aprecie o fato de não ser um transformador de consciência e muito menos um delator de opiniões, mas que considere que a superação de si mesmo como aquele que ensina é um exemplo a ser observado, não a ser seguido. O professor é um exemplo a ser dado aos sentidos, aos instintos, para que na solidão do estudante seja feita realmente a superação de si, ou seja, o seu ensino mesmo.

\section{Referências bibliográficas}

DELEUZE, Gilles. Abecedário Gilles Deleuze, $\mathrm{P}$ de professor, parte 3, acessível em: https://www.youtube.com/watch?v=hQ6fOKClnc8

NIETZSCHE, Friedrich. A gaia ciência. Trad., notas e posfácio de Paulo Cesar de Souza. São Paulo: Companhia das Letras, 2001.

Além do bem e do mal: prelúdio de uma filosofia do futuro. Trad., notas e posfácil de Paulo César de Souza. São Paulo: Companhia das Letras, 2005.

Assim falou Zaratustra: um livro para todos e para ninguém. Trad., notas e posfácio de Paulo Cesar de Souza. São Paulo: Companhia das Letras, 2011.

Genealogia da moral. Trad., notas e posfácio de Paulo Cesar de Souza. São Paulo: Companhia das Letras, 2009. 